\title{
Model Pembelajaran Inovatif di Era Revolusi Industri 4.0 Bagi Pengawas Sekolah Dasar Kabupaten Ciruas, Banten
}

\author{
Niko Sudibjo ${ }^{1 *}$, Luluk Asmawati², Moh. Fachri Yasin ${ }^{3}$ \\ ${ }^{1}$ Universitas Pelita Harapan \\ ${ }^{2}$ Universitas Sultan Ageng Tirtayasa \\ ${ }^{3}$ Universitas Islam Asyafi'iah \\ Email: niko.sudibjo@uph.edu \\ *Corresponding author: penulis ${ }^{1}$
}

\begin{abstract}
ABSTRAK
Berbagai perubahan akibat dampak dari revolusi industry 4.0 tidak dapat dihindari, termasuk dalam sector pendidikan. Oleh sebab itu, para pemimpin di Lembaga Pendidikan perlu terus melakukan penyesuaian agar dapat mengikuti perkembangan zaman. Salah satu perubahan yang dimaksud adalah perubahan pada model pembelajaran. Model pembelajaran menjadi sangat penting karena bersinggungan langung dengan proses belajar kelas dan berpengaruh pada ketercapaian tujuan pembelajaran. Oleh sebab itu, seminar model pembelajaran inovatif di era 4.0 diberikan untuk memberikan pemahaman mengenai metode-metode pembelajaran yang sesuai dan dapat diterapkan, diantaranya adalah blended learning, flipped classroom dan Technological, Pedagogical, Content Knowledge (TPACK). Peserta dalam seminar ini adalah para pengawas Sekolah Dasar Kabupaten Ciruas, Banten sebanyak 86 orang. Hasil dari angket menunjukkan bahwa seminar yang diberikan sangat relevan dan memberikan manfaat bagi profesi peserta seminar saat ini.
\end{abstract}

Kata kunci: blended learning, flipped classroom, technological, pedagogical, content knowledge (TPACK), revolusi industry 4.0.

\section{Innovative Learning Models in the Era of the Industrial Revolution 4.0 for Elementary School Supervisors in Ciruas Regency, Banten}

\section{ABSTRACT}

Various changes due to the impact of the industrial revolution 4.0 cannot be avoided, including in the education sector. Therefore, leaders in Educational Institutions need to continue to adjust in order to keep abreast of the times. One of the changes in question is a change in the learning model. The learning model becomes very important because it is directly related to the class learning process and affects the achievement of learning objectives. Therefore, a seminar on innovative learning models in the 4.0 era was given to provide an understanding of appropriate and applicable learning methods, including blended learning, flipped classroom and Technological, Pedagogical, Content Knowledge (TPACK). The participants in this seminar were the supervisors of 86 elementary schools in Ciruas, Banten. The results of the questionnaire showed that the seminar given was very relevant and provided benefits to the current seminar participant profession.

Keywords: blended learning, flipped classroom, technological, pedagogical, content knowledge (TPACK), industrial revolution 4.0. 


\section{PENDAHULUAN}

Era revolusi industry 4.0 yang diwarnai dengan perkembangan teknologi yang pesat, perubahan yang cepat dan tidak menentu, kompetisi yang tinggi dalam berbagai sektor bisnis, system produksi yang terintegrasi, memberikan dampak hampir diseluruh aspek kehidupan manusia, tak terkecuali sektor pendidikan (Mukminan, 2015; Salkin et al, 2018). Hampir di seluruh aspek kehidupan berusaha mempercepat akses pertukaran informasi, guna meningkatkan efektivitas dan efisiensi dalam segala bidang pekerjaan. Gaya hidup masyarakat di era revolusi industry 4.0 juga turut serta mengalami perubahan, dimasa saat ini semua berfokus pada aspek kemudahan dan kepuasan layanan jasa, yang sangat banyak dipengaruhi oleh teknologi, misalnya transportasi online, pemesanan makanan online, logistic, e-commerce, dan sebagainya (Sudibjo, Idawati \& Harsanti, 2019).

Trend kemudahan da kepuasan layanan jasa di era revolusi industry 4.0 juga membawa perubahan secara khusus dalam sektor pendidikan, dimana focus pendidikan adalah self-centred learning (Mukminan, 2015). Lembaga pendidikan berusaha menyediakan jasa pendidikan yang sesuai dengan kebutuhan pembelajar, dan disajikan dengan berbagai fitur kemudahan yang dapat ditunjang dengan teknologi. Arah pembelajaran juga disesuaikan dengan minat belajar para peserta didik yang juga mengalami perubahan yang dipengaruhi oleh perkembangan dan perubahan dalam jenis pekerjaan ada. Berbagai pekerjaan baru muncul di era saat ini yang banyak berkaitan dengan teknologi dan menjadi trend, misalnya seperti copywriter, vlogger, youtuber, content writer, social media officer, dan lain sebagainya (Sudibjo, Idawati \& Harsanti, 2019).

Perkembangan teknologi yang pesat dan terjangkau bagi masyarakat turut merambah dunia peserta didik, dimana mereka hampir seluruhnya memiliki akses yang mudah terhadap teknologi. Peserta didik dapat dengan mudah memperoleh informasi yang diinginkan dengan bantuan teknologi salah satunya internet. Trend pengetahuan di era teknologi menekankan pada akses belajar yang memfasilitasi orang mengejar hasrat dan tujuan mereka, dan untuk menyediakan ruang belajar yang luas untuk mempelajari apa yang mereka pilih, serta mampu menjadi tipe orang yang mereka inginkan (Collins \& Halverson, 2018).

Perubahan trend pendidikan yang tidak dapat dihindari di era revolusi industry 4.0 mejadikan para pemimpin di Lembaga pendidikan untuk dapat menyesuikan diri. Salah satunyaadalah terkait dengan model pembelajaran yang disajikan bagi para peserta didik. Menyadari begitu pentingnya untuk memahami model pembelajaran yang cocok bagi pendidikan di era revolusi industry 4.0, para pengawas sekolah dasar di Kabupaten Ciruas, Banten, berupaya untuk memperlengkapi diri untuk menambah wawasannya terkait dengan metode belajar di era revolusi industry 4.0. Oleh sebab itu, kerja sama 
dilaksanakan antara dewan pengawas sekolah dasar di Kabupaten Ciuras, Banten, dengan gabungan Program Studi Magister Teknologi Pendidikan Universitas Sultan Ageng tirtayasa, Universitas Pelita Harapan, dan Universitas Islam As-syafi'iyah untuk menyelenggarakan seminar mengenai model pembelajaran inovatif di era industri 4.0. Dari berbagai metode pembelajaran yang ada, seminar ini berfokus pada blended learning, flipped classroom dan Technological, Pedagogical, Content Knowledge (TPACK).

Blended learning adalah strategi pembelajaran dengan penggabungan pembelajaran konvensional dengan pembelajaran berbasis teknologi informasi, dengantujuanmenghasilkan pembelajaran yang efektif dengan kualitas interaksi yang baik antara dosen dengan peserta didik (Divayana, 2019). Sejalan dengan itu, Sofiana (2015) menyebutkan bahwa blended leraning melibatkan pembalajaran mandiri oleh peserta didik yang dipadukan dengan pembelajaran tatap muka yang didikung dengan bantuan teknologi dalam proses pembelajaran. Pembelajaran dengan blended learning diyakini dapat memberikan pengalaman belajar yang mandiri dan menyenangkan.

Flipped classroom adalah model belajar yang "dibalik" dimana kebiasaan penjelasan pelajaran di kelas dibalik dilakukan di rumah dengan bantuan teknologi sehingga waktu yang dimiliki di kelas dapat dimaksimalkan untuk aktivitas seperti mengerjakan tugas, pertanyaan latihan, proyek, atau diskusi terkait dengan materi (Mas'ud \& Surjono, 2018). Penjelasan materi yang biasa dilakukan di kelas, diubah menjadi rekaman video pembelajaran seperti rekaman guru mengajar, atau videovideo pembelajaran lain, yang dapat diakses oleh siswa di rumah (Ishak, Kurniawan \& Zainudin, 2019). Tujuannya adalah agar waktu belajar di sekolah dapat dimaksimalkan untuk kegiatan yang lebih melibatkan keaktifan siswa.

Technological Pedagogical and Content Knowledge (TPACK) merupakan kombinasi dari kerangka pembelajaran antara pengetahuan konten pembelajaran, pengetahuan teknis interaksi dan komunikasi dalam pembelajaran, pengetahuan metodologis pengajaran, dan teknologi informasi (Tian, et al., 2017). TPACK merupakan konsep dimana guru diharapkan mampu menyampaikan konten pembelajaran dengan kompetensi pedagogi dan juga melibatkan bantuan teknologi agar menjadi efektif dan efisien. Ketiga kompnenen dalam TPACK yaitu konten, pedagogi dan teknologi akan menjadi efektif ketika terjadi kolaborasi dan interkasi antar ketiganya sehingga menghasilkan berbagai inovasi pembelajaran yang luas dan berkualitas (Sukaesih, Ridlo \& Saptono, 2017).

Seminar model pembelajaran inovatif di era revolusi industri 4.0. dilaksanakan pada tanggal 17 Februari 2020 dengan menggunakan Gedung PGRI Kabupaten Ciruas sebagai lokasinya. Adapun seminar ini 
untuk menindaklanjuti undangan dari Universitas Sultan Ageng Tirtayasa sebagai koordinator pelaksana seminar kerja sama dengan dewan pengawas Sekolah Dasar Kabupaten Ciruas, dengan nomor 094/UN43.13.2/ TPM/2020 yang disampaikan pada tanggal. Tujuan dari seminar ini adalah memberikan pemahaman mengenai metode pembelajaran yang cocok dan dapat diterapkan di era revolusi industry 4.0.

\section{METODE PELAKSANAAN}

Seminar dilaksanakan bagi pengawas sekolah dasar Kabupaten Ciruas, dengan jumlah peserta 86 orang. Seminar dilaksanakan di Gedung PGRI Kabupaten Ciruas pada tanggal 17 Februari 2020. Seminar ini dilaksanakan secara gabungan dari tiga program studi Magster Teknologi Pendidikan yaitu Universitas Sultan Ageng tirtayasa, Universitas Pelita Harapan, dan Universitas Islam Asyafi'iah. Setelah seminar disampaikan, peserta diminta mengisi kuesioner kebermanfaatan seminar melalui kuesioner online. Jumlah peserta yang mengisi kuesioner adalah 44 orang, karena bersifat sukarela.

\section{HASIL DAN PEMBAHASAN}

Seminar dibuka dengan
penjelasan mengenai adanya
kebutuhan para pengawas untuk
memahami perkembangan arah
pendidikan di era revolusi industry
4.0. Pembukaan ini disampaikan oleh
sekretaris dewan pengawas sekolah
dasar kabupatan ciruas, yang berperan
sebagai moderator dalam seminar ini.
Disampaikan juga oleh moderator

mengenai kebutuhan para pengawas sekolah akan informasi mengenai model pembelajaran yang cocok di era revolusi industry 4.0. Selanjutnya panel diskusi diberikan kepada pembicara seminar.

Kegiatan seminar metode pembelajaran yang efektif di era revolusi industry 4.0 ini dibagimenjadi tiga bagian. Pertama adalah mengenai metode belajar blended learning. Pembicara memulai pemaparannya dengan mendeskripsikan karakteristik pembelajaran di era revolusi industry 4.0, dan karakteristik pembelajar di era revolusi industry 4.0 dan di era mendatang. Peserta seminar didorong untuk memikirkan bagaimana kondisi kesiapan para pendidik saat ini dalam menghadapi disrupsi teknologi khususnya dalam bidang pendidikan. Selanjutnya, pembicara menjelaskan mengenai metode belajar blended learning sebagai penggabungan mode belajar online dengan offline. Dijelaskan juga dalam penjelasan topik ini mengenai kelebihan dan kekurangan penggunaan blended learning. Pembicara juga menjelaskan mengapa metode ini cocok untuk diterapkan untuk pembelajaran di era revolusi industry 4.0. Secara lebih detail, pembicara memberikan tips dan tahapan-tahapan bagi guru dan pengawas dalam melaksanakan metode belajar blended learning. Topik ini dibawakan oleh Dr. Niko Sudibjo, S.Psi., M.A. dari Universitas Pelita Harapan. 


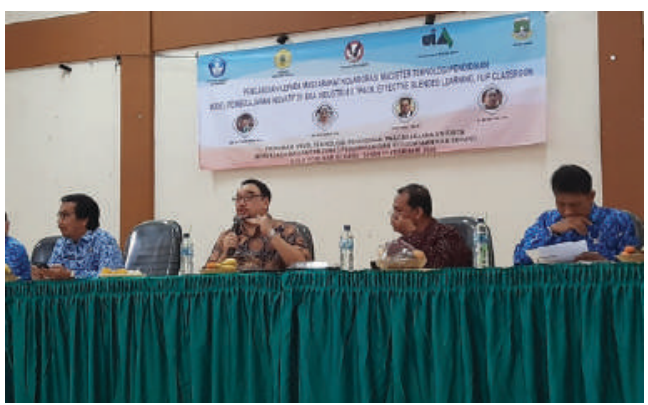

Gambar 1: Dr. Niko Sudibjo, S.Psi., M.A. menyajikan materi seminar

Sesi kedua adalah mengenai metode belajar flipped classroom. Pembicara memulai penjelasan dengan menjelaskan definisi flipped classroom dan perbedaannya dengan blended learning. Pembicara menjelaskan bagaiamana metode ini sangat cocok diterapkan di level sekolah dengan tujuan membuat pembelajaran menjadi lebih aktif dengan berbagai aktivitas. Dijelaskan juga dalam pembahasan topik ini mengenai kelebihan dan kekurangan implementasi pembelajaran dengan flipped classroom dalam konteks level sekolah dasar. Pembicara juga memberikan gambaran mengenai platform atau aplikasi pembelajaran yang dapat digunakan untuk menunjang pembelajaran dengan metode flipped classroom. Topik ini dibawakan oleh Dr. Moh. Fachri

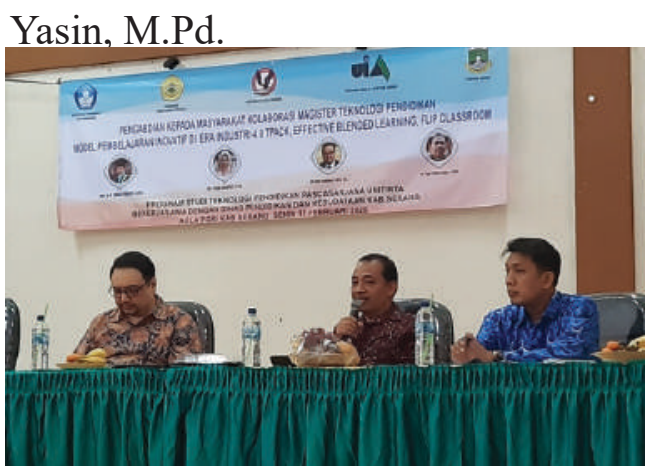

Gambar 2: Dr. Moh. Fachri Yasin,
M.Pd. menyajikan materi seminar

Sesi ketiga adalah mengenai metode belajar TPACK. Pembicara memulai penjelasan dengan pemaparan mengenai pentingnya bagi para pendidik untuk menguasai konten pembelajaran dengan penggabungan aspek pedagogi dan teknologi. Pada topik ini, pembicara berfokus pada bagaimana mengelola sebuah rancangan pembelajaran yang komprehensif agar tujuan pembelajaran dapat tercapai secara efektif dan menjadi efisien dengan penguasaan pedagogi serta teknologi. Pembicara menjelaskan mengenai pentingnya penguasaan konten sebagai bekal utama untuk para guru dalam mengajar. Selanjutnya dijelaskan juga mengenai pentingnya guru menguasai kemampuan komunikasi dan manajemen kelas, sebagai bagian dari keterampilan pedagogi. Kemudian, pembicara menekankan pentingnya penguasaan teknologi bagi guru di era revolusi industry 4.0. Pada akhir sesi, pembicara memberikan contoh bagaimana rancangan pembelajaran dengan menggabungkan ketiga aspek penting, yaitu pengetahuan konten, pedagogi dan teknologi. Topik ini dibawakan oleh Dr. Luluk Asmawati, M.Pd.

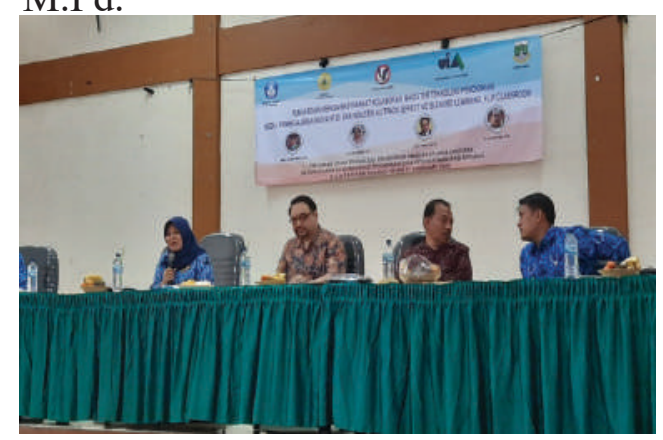

Gambar 3: Dr. Luluk Asmawati, M.Pd. menyajikan materi seminar 


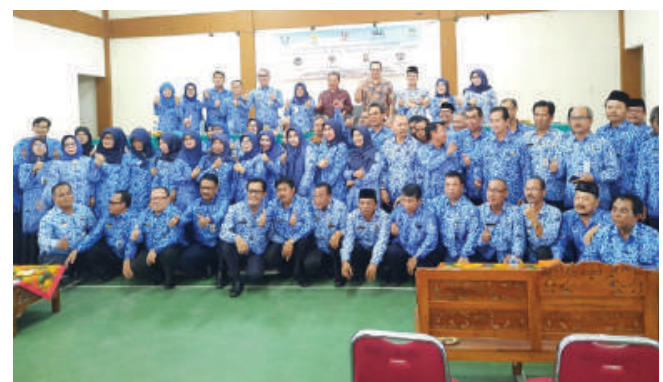

Gambar 4: Foto bersama peserta seminar dengan pembicara seminar

Setelah mengikuti sesi seminar, peserta diminta mengisi angket kebermanfaatan seminar yang diberikan. Pengisian angket dilakukan dengan kuesioner online dan bersifat sukarela. Darijumlah peserta 86 orang, peserta yang mengisi angket adalah 44 orang. Angket berisi 8 pernyataan terkait dengan pelaksaan seminar dengan pilihan jawaban berskala 1-5, dimana 1 untuk sangat setuju dan 5 untuk sangat tidak setuju. Selain itu, diberikan juga ruang terbuka untuk menuliskan masukan bagi pembicara seminar maupun pelaksanaan seminar. Hasil angket kebermanfaatan seminar dapat dilihat pada tabel 1 .

Tabel 1: Angket Kebermanfaatan Seminar

\begin{tabular}{|l|l|l|l|l|l|l|}
\hline \multirow{2}{*}{ No } & PERNYATAAN & \multicolumn{5}{|c|}{$\begin{array}{c}\text { PRESENTASE SKALA } \\
\text { (\%) }\end{array}$} \\
\cline { 3 - 8 } & & $\mathbf{1}$ & $\mathbf{2}$ & $\mathbf{3}$ & $\mathbf{4}$ & $\mathbf{5}$ \\
\hline 1 & $\begin{array}{l}\text { Seminar ini relevan } \\
\text { untuk profesi saya. }\end{array}$ & 0 & 0 & 0 & 22,73 & 77,27 \\
\hline 2 & $\begin{array}{l}\text { Topik seminar ini } \\
\text { menarik. }\end{array}$ & 0 & 0 & 0 & 4,55 & 95,45 \\
\hline 3 & $\begin{array}{l}\text { Materi seminar } \\
\text { disampaikan } \\
\text { dengan jelas. }\end{array}$ & 0 & 0 & 6,81 & 20,45 & 72,74 \\
\hline 4 & $\begin{array}{l}\text { Materi seminar } \\
\text { yang disampaikan } \\
\text { mudah dipahami. }\end{array}$ & 0 & 0 & 0 & 31,81 & 68.19 \\
\hline 5 & $\begin{array}{l}\text { Materi seminar ini } \\
\text { bermanfaat untuk } \\
\text { saya. }\end{array}$ & 0 & 0 & 0 & 22,73 & 77,27 \\
\hline 6 & $\begin{array}{l}\text { Narasumber } \\
\text { menyampaikan } \\
\text { seminar dengan } \\
\text { profesional. }\end{array}$ & 0 & 0 & 0 & 47,72 & 52,28 \\
\hline
\end{tabular}

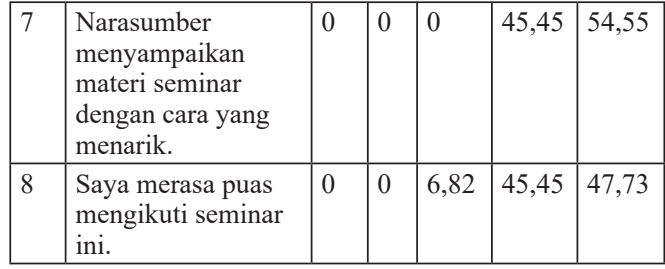

Berdasar perolehan angket, diketahui bahwa topik seminar yang diberikan yaitu metode pembelajaran yang efektif di era revolusi industry 4.0 dinilai sangat menarik bagi para perserta seminar, dengan perolehan angka 95, 45\%. Kemudian, diketahui juga sebangak $77,27 \%$ peserta seminar sangat setuju bahwa seminar yang diberikan relevan dengan prosesi peserta dan memberikan manfaat bagi mereka. Sebanyak 72,74\% peserta seminar juga menyatakan sangat setuju mengenai pembicara seminar menyampaikan materi seminarnya dengan jelas, dan $68,19 \%$ menyatakan bahwa materi seminar yang diberikan mudah dipahami.

Pada penyataan angket nomor 7 dan 8 diketahui bahwa penilaian yang diberikan responden tidak setinggi pernyataain lainnya. Hal ini dikarenakan adanya kesalahan teknis pada pelaksanaan seminar, dimana LCD projector tidak dapat digunakan. Hal ini mengakibatkan tidak adanya tampilan powerpoint penunjang. Para peserta seminar juga tidak dapat menyaksikan simulasi pengelolaan blended learning dan flipped classroom. Kondisi ini turut berdampak pada penilaian angket pada nomor 8 dimana tingkat kepuasan peserta seminar kurang maksimal, sehingga hanya $47,73 \%$ yang merasa sangat puas.

Berdasarkan angket, terdapat 
saran dari peserta seminar melalui kolom jawaban terbuka, dimana peserta seminar mengharapkan adanya workshop atau pelatihan terbimbing terkait dengan pengelolaan teknologi pembelajaran yang sudah dijelaskan dalam seminar. Menurut mereka, penjelasan mengenai platform atau aplikasi penunjang pembelajaran berbasis teknologi akan lebih mudah dipahami jika dapat dipraktikkan langsung. Beberapa perserta juga menyarankan agar durasi dapat lebih panjang agar sesi diskusi dan tanya jawab dapat berlangsung lebih banyak.

\section{SIMPULAN}

Seminar model pembelajaran inovatif di era revolusi industri 4.0: TPACK, effective blended learning, flipped classroom bagi pengawas sekolah dasar kabupaten Ciruas, Banten berlangsung dengan baik. Berdasarkan hasil angket diketahui bahwa seminar yang diberikan memberikan manfaat dan relevan bagi parapesertayangmerupakanpengawas Sekolah Dasar di Kabupaten Ciruas, Banten. Untuk kegiatan yang akan datang, para peserta menyarankan untuk diberikan workshop yang lebih aplikatif mengenai platform atau aplikasi yang dapat digunakan dalam menunjang pembelajaran berbantuan teknologi.

\section{DAFTAR PUSTAKA}

Collins, A., \& Halverson, R. (2018). Rethinking Education in The Age of Technology. New York: Teachers College Press.

Divayana, D. G. (2019). The
Implementation of Blended Learning with Kelase Platform in the Learning of Assessment and Evaluation Course. International Journal of Emerging Technologies in Learning, 14(7), 114-132.

Ishak, T., Kurniawan, R., \& Zainuddin, Z. (2019). Implementasi Model Pembelajaran Flipped Classroom Guna Meningkatkan Interaksi Belajar Mahasiswa pada Mata Kuliah Manajemen Informasi dan E-Administrasi. Edcomtech Jurnal Kajian Teknologi Pendidikan, 4(2), 109-119.

Mas'ud, H., \& Surjono, H. D. (2018). The Implementation of Flipped Classroom Learning Model Using Moodle To Increase Students'HigherOrderThinking Skills. Journal of Educational Science and Technology, 4(3), 187-194.

Mukminan. (2015). Kurikulum Masa Depan. Retrieved from http://staffnew.uny.ac.id/ upload/130682770/penelitian/ ba-32kur-masa-depansemnasuntirta16-2- 15.pdf

Salkin, C., Oner, M., Ustundag, A., \& Cevikcan, E. (2018). A Conceptual Framework for Industry 4.0. In A. Untundag, \& E. Cevikcan, Industry 4.0: Managing The Digital Transformation (pp. 3-22). Switzerland: Springer.

Sofiana, N. (2015). Implementasi blended learning pada mata kuliah extensive listening. Jurnal Tarbawi, 12(1), 59-70.

Sudibjo, N., Idawati, L., \& Harsanti, H. R. (2019). Characteristics of Learning in the Era of Industry 4.0 and Society 5.0. International Conference on Education Technology 2019 (pp. 276-278). Padang: Advances in Social Science, Education and 
Humanities Research, Vol. 372.

Sukaesih, S., Ridlo, S., \& Saptono,

S. (2017). Analisis kemampuan technological pedagogical and content knowledge (TPACK) calon guru pada mata kuliah PP Bio. Seminar Nasional Pendidikan Sains (pp. 58-64). Surakarta: Universitas Sebelas Maret Surakarta.

Tian, T., Zou, N., Jiang, J., \& Xu, X. (2017). Application of Practical CurriculumforCollegeSpecialty of Economic Management under TPACK Framework. International Journal of Emerging Technologies in Learning, 12(7), 124-135. 